\title{
Futbolcuların Piyasa Değerleri Üzerinden Menkul Kıymetleştirme Çalışması
}

\author{
Ali BAYIR \& Ayşe Hümeyra BILLGE
}

\section{Özet}

Bu çalışma ile Türkiye Süper Lig'de mücadele eden Beşiktaş, Fenerbahçe, Galatasaray ve Trabzonspor takımlarının 30.09.2019 tarihi itibari ile kadrolarında bulunan futbolcularının finansal değerleri üzerinden varlığa dayalı menkul kıymetleştirme işleminin yapılması amaçlanmıştır. Kulüplerin kadrolarında bulunan futbolcular oynadıkları mevkiilere göre kaleci, defans, orta saha ve forvet mevkileri olmak üzere 4 mevkiiye göre sınıflandırılmıştır. Çalışma için transfermarkt sitesinin verileri kullanılmış, değerlemenin yapıldığı tarihten futbolcuların doğum tarihleri çıkartılması ile yaş-ay zamanına göre transfermarkt değeri bulunmuştur. Tüm futbolcular için 16 yaş 01 ay ve 37 yaş 12 ay arasında futbol oynadıkları varsayılmıştır. Transfermarkt sitesi futbolcu değerlemelerini sürekli yapmadığı için veri olmayan yaş-ay zaman dilimi için kübik spline (şerit) interpolasyon yöntemi ile belirlenen yaş aralıkları için tüm aylar için değerler tahmin edilmiştir. Eğri uydurma işlemi için Eviews 10 programı kullanılmıştır. Çalışmada 4 takım için de kaleci, defans, orta saha ve forvet mevkiinde oynayan futbolcuların değerlerinin en yüksek olduğu yaş-ay zamanı tespit edilmiştir. Transfermarkt verilerine göre Galatasaray takımı kadrosunda bulundurduğu futbolcular ile birlikte en değerli takım olduğu tespit edilmiştir. Ayrıca fonksiyon ile elde edilen verilere göre de tüm mevkiiler için en yüksek ortalamaların da Galatasaray takımına ait olduğu görülmüştür. Elde edilen verilere göre Trabzonspor takımının kaleci mevkii için menkul kıymetleştirme işlemi yapılmış ve bir örnek ile açıklanmaya çalışılmıştır.

Anahtar Kelimeler: Finans, Finansal Türev Ürünler, Futbol, Menkul Kıymetleştirme, Varlığa Dayalı Menkul Kiymet.

\section{Securitization Study Of Football Players Over Market Values}

\begin{abstract}
This study aims to Turkey Super League competetor Besiktas, Fenerbahce, Galatasaray and Trabzonspor based on the value of financial assets out of the players who team with a staff of date 30.09.2019 has exploratory to securitization process. The players in the clubs are classified according to the positions they play in 4 positions; goalkeeper, defender, midfielder and forward. The data on the Transfermarkt website were used for the study and the value of the players birth date was subtracted from the date of the valuation by age-month time. It is assumed that for all players, they play football between 16 years 01 months and 37 years 12 months. For the nondata age-month time period, values were estimated for all months for the age ranges determined by cubic spline interpolation method, since the Transfermarkt website did not make continuous player evaluations. Eviews 10 program was used for curve fitting. according to the positions they play in 4 positions; goalkeeper, defender, midfielder and forward. The data on the Transfermarkt website were used for the study and the value of the players birth date was subtracted from the date of the valuation by age-month time. It is assumed that for all players, they play football between 16 years 01 months and 37 years 12 months. For the non-data age-month time period, values were estimated for all months for the age ranges determined by cubic spline interpolation method, since the Transfermarkt website did not make continuous player evaluations. Eviews 10 program was used for curve fitting.In the study, age-month time of the players who played in goalkeeping, defender, midfielder and striker positions for all 4 teams was determined. According to data from Transfermarkt, Galatasaray team was found to be the most valuable team along with the players it had in its squad. In addition, according to the data obtained by the function, the highest averages for all positions were also found to belong to Galatasaray team. According to the data obtained, the Securitization process was performed for the goalkeeping position of Trabzonspor team and tried to be explained with an example.
\end{abstract}

Keywords: Finance, Financial Derivatives, Football, Securitization, Asset-Based Securities

\footnotetext{
1 Yüksek lisans mezunu, Kadir Has Üniversitesi, Finans Mühendisliği Bölümü, alibayir82@hotmail.com

2 Prof. Dr., Kadir Has Üniversitesi, Mühendislik ve Doğa Bilimleri Fakültesi, ayse.bilge@khas.edu.tr
} 


\section{Giriş}

Menkul kıymetler, sahibine ortaklık veya alacaklılık hakkı sağlayan belirli bir tutarı temsil eden yatırım aracı olarak kullanılan, dönemsel getiri sağlayan, misli nitelikte olan seri halde çıkartılan, ibareleri aynı olan ve şartları Sermaye Piyasası Kanun'da belirtilen kıymetli evrak olarak tanımlanmıştır. Menkul kıymetleştirme (seküritizasyon) ise şirketin sahip olduğu varlıkları menkul kıymet haline dönüştürülmesi işlemi olup, bu sayede sermaye piyasalarından yeni bir enstrüman aracılığı ile finans sağlamasıdır. (Tüysüz, 2011: 37-38)

Menkul kıymetleştirme işlemi kredi kartı alacakları, ticari krediler, taşıt kredileri, konut finansmanı kredileri gibi düşük likiditesi olan alacakların finansal yapılandırma tekniklerinin kullanılmasıyla tek bir havuzda toplanıp yüksek likiditeli varlıklara dönüştürülmesidir. Menkul kıymetleştirme 1970'li yılların ortalarından itibaren Amerika Birleşik Devletleri'nde (ABD) gelişmeye başlamıştır. İlk ortaya çıktığı zamanlarda ipoteğe bağlı alacaklar menkul kıymetleştirilmiştir. (Öcal, 1994: 5) 1985 yılında Sperry Corportation firması 192,5 milyon dolar değerindeki finansal kiralama sözleşmelerinden doğan alacaklarını menkul kıymetleştirilmesi ile birlikte ilk kez ipoteğe bağlı olmayan aktife dayalı menkul kıymet (Asset-Backed Securities) ihracı gerçekleştirilmiştir.(Minton, Opler ve Stanton, 1997:3)

Menkul kıymetleştirme işlemine dayanak olarak bir çok varlık kullanılabilir. Bunlar arasında en ilginçlerinden birisi de İngiliz sanatçı David Bowie'nin 255 adet şarkısından oluşan bir varlığın menkul kıymetleştirilmesidir. 1997 yılında ihraç edilen Bowie Bond's olarak adlandırılan bu işlemde ihraç edilen tahvillerin 55 Milyon dolar gelir elde edilmiştir. Tahvillerin vadesi 15 yıl olup \% 7.9 faiz ile ihraç edilmiştir.(Burke Slyva, 1999: 196-230)

Likit olmayan varlıkların nakde çevrilmesine olanak sağlayan menkul kıymetleştirmeden futbol kulüpleri de faydalanmaya çalışmışlardır. 1999 yılının Aralık ayında İngiliz Newcastle United kulübü maçlarını oynadığ 1 St. James Park stadından elde edeceği bilet satış gelirlerini menkul kıymetleştirerek ihraç etmiş ve 55 Milyon sterlin gelir elde etmiş̧ir. (Weston, 2002: 49-52) 2001 yılının sonuna kadar 5 kulüp daha (Ipswich Town, Leicester City, Southampton, Everton ve Leeds United) Newcastle United kulübünü takip ederek bilet gelirlerini dayanak varlık göstererek menkul kıymetleştirerek bunları ihraç etmişlerdir. (Burns, 2007: 1-12)

Aktife dayalı menkul kıymetler ikincil piyasalarda da alınıp satılmasına olanak sağladığı için finansal piyasaların büyümesine ve gelişmesine neden olmaktadır. Menkul Kıymetler Endüstrisi ve Finansal Piyasalar Birliği’nin (SIFMA) yayınladığı rapora göre 2018 yılı sonu itibari ile ABD'de varlığa dayalı menkul kıymetlerin büyüklüğü 516,92 milyar dolardır. 2019'un ilk 8 ayı ile geçtiğimiz yılın aynı dönemini kıyasladığımızda toplam VDMK (ABS) büyüklüğü \% 44 gerileyerek 209,95 milyar dolar olarak gerçekleşmiştir. (SIFMA, 2019) 
$\mathrm{Bu}$ çalışmada futbol kulüplerinin kadrolarında yer alan futbolcularının piyasa değerleri üzerinden yeni bir finansal araç modellenerek incelenmiştir. Çalışmanın ikinci bölümünde futbol kulüpleri için menkul kıymetleştirme işlemine dayanak olacak varlıklar ile ilgili literatür taraması yapılmıştır. Üçüncü bölümünde çalışma için kullanılan veriler ile birlikte çalışmanın metodu ve yöntemi ele alınmıştır. Dördüncü bölümde çalışma ile ilgili elde edilen bulgular açıklanmış ve tartışılmıştır.

\section{Literatür Taraması}

Futbol kulüplerinin sahip olduğu varlıkların menkul kıymetleştirilmesi ile alakalı akademik çalışmalar yapılmıştır. Ancak bu çalışmalar kulüplerin, futbol maçlarını oynadıkları stadyum gelirlerine ilişkin kıymetlerin ihraç edilmeleri hakkında olmuştur.

Tom Burns (2007) yapmış olduğu çalışmada 1999 yılında İngiltere Premier Liginde (EPL) mücadele eden Newcastle United takımının bilet ve gişe gelirlerini menkul kıymetleştirerek 55 Milyon sterlin gelir elde etmesini sonrasında ise diğer takımlarının Newcastle United takımını takip etmesini ancak menkul kıymetleştirme sözleşmelerinin kulüplerin yükümlülüklerini yerine getirmede yetersiz kalmasından dolayı yatırımcıların takımlara olan güvenlerini kaybetmelerine neden olmuştur. Menkul kıymetleştirmenin hala futbol kulüpleri için bir seçenek olmasına rağmen yatırımcıların istekli olabilmeleri için belirli bir eşik değerinin üzerindeki varlıkları talep etmesinin muhtemel olmasına ve takımların sahada elde edecekleri başarılara bağlı olduğunu belirtmiştir.

Rae Weston'ın (2002) çalışmasında kulüplerin bilet gelirleri ile menkul kıymetleştirilen varlık arasında farklar olabildiğini Avrupa kupalarına katılan takımların daha büyük kalabalıkları cezbettiğini, kupalara katılamayan takımların ikinci bir seviyede olduğu alt ligde oynayan takımların ise üçüncü bir seviyeye indiğini dolayısı ile taraftarları cezbetmediğini bahsetmektedir. Weston potansiyel yatırımcıların bu tür menkul kıymetleştirmeler için dikkat edilmesi gereken 2 konu olduğunu söylemektedir. Birincisi kulüpler menkul kıymetleştirme ile elde ettikleri fonlar ile yeni oyuncu yatırımı yaparak uzun vadede fayda sağlamaktadırlar, ikinci olarak da hem EPL'de hem de Avrupa kupalarında mücadele eden takımların taraftarları maçlara gitmeye daha fazla ilgi göstereceklerinden bahsetmiştir.

2010 yilında Hongquan Li, Houzhong Jin ve Dan Wang Çin'de yapılacak büyük stadyumların inşasının finansmanında yap işlet devret, kamu özel işbirliği gibi modeller ile varlığa dayalı menkul kıymetleştirme modelinin karşılaştırmasını yapmış Çin'in gelişen piyasa ekonomisi ile birlikte finans modellerinin çeşitlendirilmesini ve stadyum inşaatında ve işletilmesinde menkul kıymetleştirilme modelinin desteklenmesi gerektiğini söylemiştir.( Hongquan Li, Houzhong Jin ve Dan Wang,2011: 90-92)

2019 yılında Matteo Maciel ve Adam Walton yaptıkları çalışmada futbolcuların ekonomik değerlerinin teminat olarak kullanılıp kullanılamayacağını araştırmışlardır. FIFA'nın 1 Mayıs 2015 
tarihinden itibaren geçerli olan düzenlemesine göre hiçbir kulüp ve ya oyuncu, oyuncunun gelecekte başka bir kulübe transferi nedeni ile ödenecek tazminatın tümü ve ya bir kısmı üzerinden üçüncü kişilerin hak sahibi olabilmesi için üçüncü kişiler ile bir sözleşme ilişkisine giremeyeceği belirtilmiştir. (FIFA, 2015: 20-21) Maciel ve Walton oyuncunun ekonomik haklarının değerini kullanarak kredi verecekler açısından nasıl teminatlandırılabileceği araştırmış Uluslararası Futbol Federasyonları Birliği'nin (FIFA) transfer düzenlemesi ile birlikte İngiltere ve Galler Futbol Federasyonunun aynı konuya ilişkin düzenlemelerini hukuki boyutlarını incelemişlerdir. Kulüplerin diğer kulüplerle ile rekabet edebilmesi için oyuncuların ekonomik değerlerinin teminatlandırılması ile yeni finansal kaynak oluşturulabileceğini belirtmişlerdir. (Maciel ve Walton, 2019: 185-209)

Bu çalışmada kulüplerin kadrolarında yer alan futbolcuların ekonomik değerleri üzerinden oluşturulacak bir menkul kıymetleştirme işlemi ile yeni bir finansal ürün elde edilmeye çalışılarak literatüre katkı yapılması hedeflenmiştir.

\section{Veri Seti ve Yöntem}

\subsection{Veri}

Çalışmada Türkiye' de 4 büyükler olarak adlandırılan ayrıca hisseleri Borsa İstanbul'da işlem gören Beşiktaş, Fenerbahçe, Galatasaray ve Trabzonspor takımlarının 30.09.2019 sonu itibari ile kadrolarında yer alan futbolcularının www.transfermarkt.com sitesindeki piyasa değerleri veri seti olarak kullanılmıştır.

Transfermarkt 2000 yılından beri dünya üzerindeki birçok ülkenin futbol takımlarında oynayan futbolcuların piyasa değerlerini tahmin etmeye çalışan Almanya menşeili bir internet sitesidir. Çalışma kapsamında transfermarkt sitesi tarafından farklı tarihlerde futbolcular için yapılan değerlemeler için, değerlemenin yapıldığı tarihten futbolcunun doğum tarihi çıkartılarak futbolcunun değerinin yaşına bağlı olarak değişim gösteren bir fonksiyon olduğu varsayılmıştır.

Şekil 1: Burak Yılmaz Piyasa Değeri (Euro)(Transfermarkt, 2019)

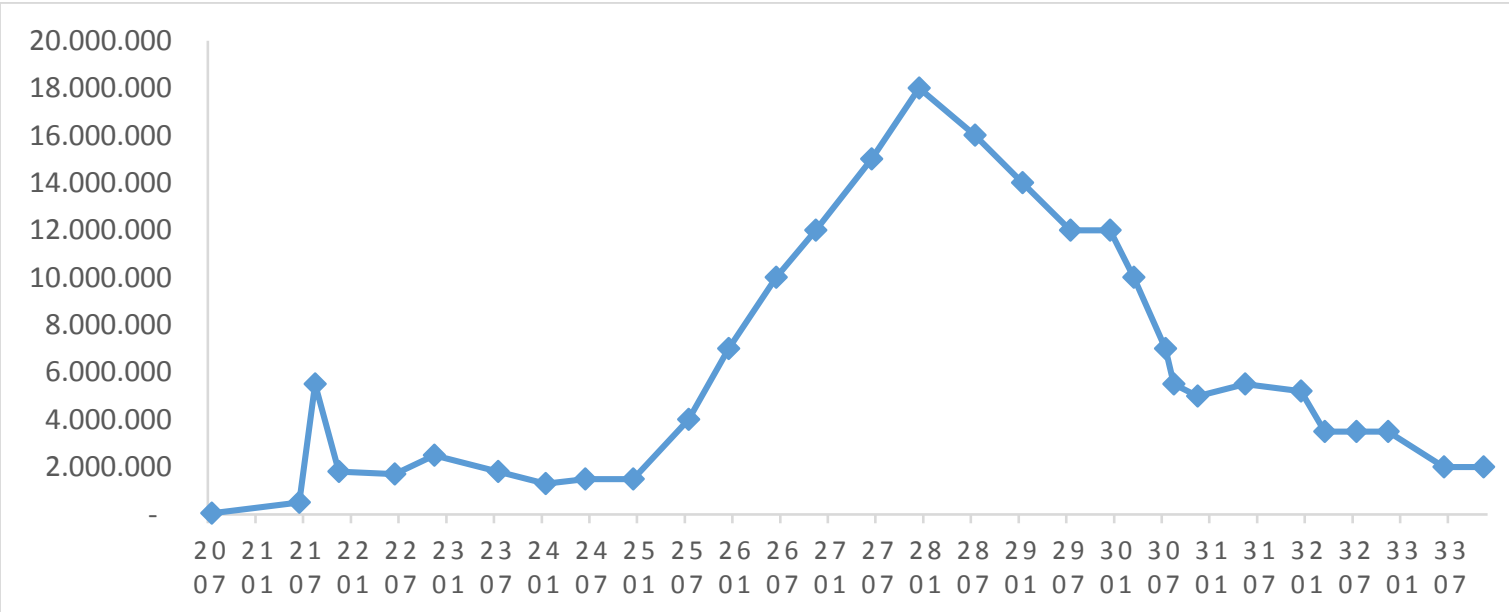




\subsection{Yöntem}

Menkul kıymetleştiryi yaparken bir şirketin sahip olduğu varlıkları menkul kıymet haline getirerek ihraç edilmesi olarak tanımlamıştık. Ayrıca menkul kıymetleştirme ile ticari faaliyet gösteren kurum gelecekte elde edebileceği gelirleri de karş1lık göstermek sureti ile borçlanma senetleri ihraç edebilir ve bu şekilde finansman sağlayabilir. Futbol kulüpleri kadrolarında yer alan futbolcuların piyasa değerleri üzerinden bir menkul kıymetleştirme işlemi yapabilmesi için gelecekte oluşabilecek nakit akımlarına bilmesi gerekmektedir. Dolayısı ile gelecekteki piyasa değerlerinin de ölçülmesi gerekmektedir. Futbolcuların güncel piyasa değeri verileri transfermarkt sitesinden sağlanabilmektedir. Ancak site bu ölçümleri belirli olmayan aralıklarda yapmakta ve iki farklı ölçüm zamanı arasında 1 yılı aşkın sürelerin olduğu gözlemlenmektedir.

Menkul kıymetleştirme yapılırken kulüpler gelecekte elde edilebilecekleri nakit akımlarında futbolcuların piyasa değerlerinin en yüksek olduğu yaş-ay zamanını ölçmeleri gerekmektedir. Futbolcuların her bir yaş-ay zamanının değeri kübik spline (şerit) interpolasyon yöntemi ile ölçülmüş ve tüm yaş-ay değerleri tespit edilmiştir.

Spline fonksiyonlar özellikleri sebebi ile bilgisayar yardımıyla yapılan hesaplamalarda kolaylıklar sağlamaktadırlar. Interpolasyon, veri ve eğri uydurma gibi birçok uygulamada yaygın bir şekilde kullanılmaktadırlar.(Doğan, 2013: 4) Bu yöntem ile birçok noktadan geçen polinom uydurmak yerine her bir $\left[\mathrm{X}_{\mathrm{i}}, \mathrm{X}_{\mathrm{i}+1}\right]$ aralı̆̆ından geçen bir üçüncü dereceden bir polinom uydurulur. Polinomun, 1. ve 2. türevlerinin $X_{i}, X_{i+1}$ noktalarında sürekli olduğu kabul edilir. (Yükselen, 2008) Buna göre

$$
S_{i}(x)=a_{0}+a_{1}\left(x-x_{i}\right)+a_{2}\left(x-x_{i}\right)^{2}+a_{3}\left(x-x_{i}\right)^{3}
$$

olarak tanımlanırsa, polinomun birinci ve ikinci türevleri

$$
S_{i}{ }^{\prime}(x)=a_{1}+2 a_{2}\left(x-x_{i}\right)+3 a_{3}\left(x-x_{i}\right)^{2}
$$

$$
S_{i}^{\prime \prime}(x)=2 a_{2}+6 a_{3}\left(x-x_{i}\right)
$$

durumuna gelir. İkinci türevin $\mathrm{X}_{\mathrm{i}}$ ve $\mathrm{X}_{\mathrm{i}+1}$ uçları sırası ile $\mathrm{M}_{\mathrm{i}}$ ve $\mathrm{M}_{\mathrm{i}+1}$ olarak adlandırabiliriz.

$$
S_{i}{ }^{\prime \prime}\left(x_{i}\right)=M_{i}=2 a_{2}, \quad S_{i}{ }^{\prime \prime}\left(x_{i+1}\right)=M_{i+1}=2 a_{2}+6 a_{3}\left(x_{i+1}-x_{i}\right)
$$

buradan da

$$
a_{2}=\frac{M_{i}}{2}, a_{3}=\frac{M_{i+1}-M_{i}}{6\left(x_{i+1}-x_{i}\right)}, \quad h_{i}=x_{i+1}-x_{i}, a_{3}=\frac{M_{i+1}-M_{i}}{6 h_{i}}
$$


şeklinde tanımlanabilir. Fonksiyonun $X_{i}$ ve $X_{i+1}$ uç noktalarında $f_{i}$ ve $f_{i+1}$ değerlerinin aldığını varsayarsak,

$$
\begin{gathered}
f_{i}=a_{0}, f_{i+1}=a_{0}+a_{1} h_{1}+a_{2} h_{i}^{2}+a_{3} h_{i}^{3} \\
a_{1}=\frac{f_{i+1}-f_{i}}{h_{i}}-\frac{2 M_{i}+M_{i+1}}{6} h_{i}
\end{gathered}
$$

bağlantısı sağlanmış olur. Kübik fonksiyonların birinci türevlerinin uç noktalarının sürekli olacağı koşuluna bağlı olarak (Yükselen, 2008)

$$
g_{i-1}{ }^{\prime}\left(x_{i}\right)=g_{i}{ }^{\prime}\left(x_{i}\right)
$$

eşitliği sağlandığında

$$
g_{i-1}^{\prime}\left(x_{i}\right)=a_{1-i}+2 a_{2 i-1} h_{i-1}+3 a_{3 i-1} h_{i-1}^{2}
$$

Denkleme katsayıları yerleştirdiğimizde aşağıdaki denklemi elde ederiz.

$$
\begin{aligned}
& \frac{f_{i}-f_{i-1}}{h_{i-1}}-\frac{2 M_{i-1}+M_{i}}{6} h_{i-1}+2 \frac{M_{i-1}}{2} h_{i-1}+3 \frac{M_{i}-M_{i-1}}{6} h_{i-1} \\
& =\frac{f_{i+1}-f_{i}}{h_{i}}-\frac{2 M_{i}+M_{i+1}}{6} h_{i}
\end{aligned}
$$

bu denklemi sadeleştirdiğimizde

$$
g_{i-1}^{\prime}\left(x_{i}\right)=a_{1-i}+2 a_{2 i-1} h_{i-1}+3 a_{3 i-1} h_{i-1}^{2}
$$

buradan da

$$
h_{i-1} M_{i-1}+2\left(h_{i-1}+h_{i}\right) M_{i}+h_{i} M_{i+1}=6\left[\frac{f_{i+1}-f_{i}}{h_{i}}-\frac{f_{i}-f_{i-1}}{h_{i}}\right]
$$

denklemine ulaşı1ır. Son olarak denklemi uç noktaları hariç bir düzenleme yaptığımızda

$$
\begin{gathered}
L_{i} M_{i-1}+D_{i} M_{i}+U_{i} M_{i+1}=R_{i}, \quad(i=1,2,3 \ldots N-1) \\
L_{i}=h_{i-1}, D_{i}=2\left(h_{i-1}+h_{i}\right), U_{i}=h_{i}, \quad R_{i}=6\left\lceil\frac{f_{i+1}-f_{i}}{h_{i}}-\frac{f_{i}-f_{i-1}}{h_{i-1}}\right\rceil
\end{gathered}
$$

Elde edilen formül kullanılarak bir futbolcunun 16 yaş 01 ay ile 37 yaş 12 ay arasında yer alan herhangi bir zaman dilimi için transfermarkt değerinden bağımsız olarak futbolcunun piyasa değeri tahmin edilebilir. Bu şekilde herhangi bir futbolcu için 16 yaş 01 ay zamanında 20.000 Euro 
değerinden başlayarak 16 yaş 02 ay, 16 yaş 03 ay şeklinde devam eden 37 yaş 12 ay zamanında yine 20.000 Euro değeri ile biten 3. dereceden bir polinom elde etmiş oluruz.

\subsection{Uygulama}

Her bir takım için kaleci, defans, orta saha ve forvet mevkiilerinde oynayan futbolcuların transfermarkt değerleri tespit edildikten sonra fonksiyondan daha düzgün sonuçlar elde etmek için futbolcuların futbola başladığı yaş ve futbolu bırakacakları yaş için bir değer verilmesi gerekmektedir. Bu çalışmamızda tüm futbolcuların futbola başladığı yaş-ay zamanını 16 yaş 01 ay ve bıraktıkları yaş-ay zamanını ise 37 yaş 12 ay olarak belirlenmiştir. Futbolcuların yaptıkları iş ve oynadıkları takımları göz önünde bulundurulmasından ötürü başlangıç ve bitiş zamanlarının finansal değeri olarak 20.000 Euro tutarı hesaplamalara dahil edilmiştir. Bu tutarlar hesaba katılırken 2018 yılında ülkemizde kişi başına düşen milli gelirin 9.632 dolar (Ticaret Bakanlığ1, 2019) olduğu tespit edilmiştir.

Başlangıç ve bitiş aralıkları belirlendikten sonra Eviews 10 programı yardımı ile diğer tüm yaş-ay zamanı değerleri kübik spline (şerit) fonksiyonu kullanılarak hesaplanmıştır. Bu işlem tamamlandıktan sonra takımların kadrolarında yer alan futbolcuların mevkiilerine göre yaş-ay zamanı için piyasa değerlerinin en yüksek olduğu tutarı buluruz. Örnek verecek olursak Galatasaray takımının orta saha mevkiinde oynayan futbolcularının piyasa değerleri üzerinden oluşturulacak menkul kıymetleştirme işlemi aşağıda gösterilen denklem ile ilgili mevkiinin tüm futbolcuların piyasa değerlerinin en yüksek olduğu yaş-ay zaman değeri tespit ederiz. Sonrasında o mevkiide oynayan futbolcuların sayısına böler ve orta saha mevkiinde oynayan futbolcular için ihraç edilecek menkul kıymet için en uygun yaş-ay zaman değerini buluruz.

$$
f t_{\text {yaş-ay }}=\frac{\sum f t_{\text {orta saha }}}{n}, \text { mak }_{\text {orta saha }}\left(f t_{\text {yaş-ay }}\right)
$$

Burada

$\mathrm{ft} \quad$ : Orta saha mevkiinde oynayan bir futbolcunun her bir yaş-ay zamanındaki finansal tutarı

n : Galatasaray takımının kadrosundaki orta saha mevkiinde oynayan futbolcularının sayısı

mak : Her bir yaş-ay zamandaki finansal değerin en yüksek tutarını

vermektedir. 
Şekil 2: Galatasaray Takımı Orta Saha Mevkii Ortalama Tahmini Değeri (Euro)

\section{Orta Saha}

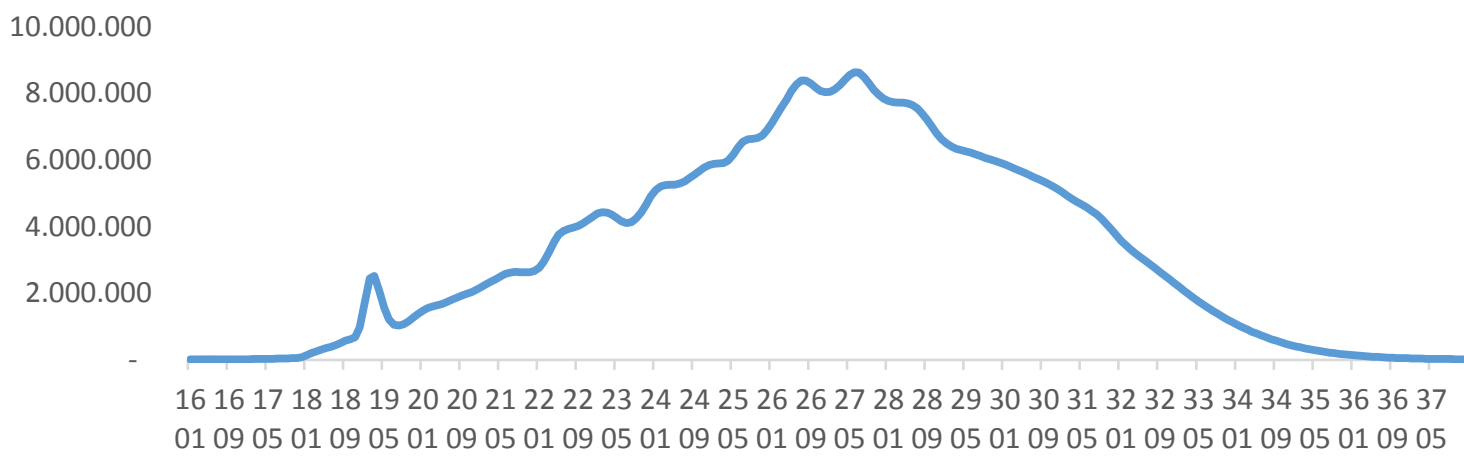

Galatasaray takımının 30.09.2019 tarihi itibari ile orta saha mevkiinde oynayan 14 futbolcusunun ortalama transfermarkt değeri 6.685.714 Euro değerlemenin yapıldığı tarihlere göre yaş-ay ortalaması ise 27 yaş 04 ay olarak ölçülmüştür. Ancak şekil 2'yi incelediğimizde fonksiyon yardımı ile bulduğumuz sonuçlara göre Galatasaray takımının bu mevkii için kadrosunda bulunan 14 futbolcusunun piyasa değerinin en yüksek olduğu zamanı 27 yaş 06 ay ve tutarının da 8.635.640 Euro olması gerektiği hesaplanmıştır.

Beşiktaş, Fenerbahçe, Galatasaray ve Trabzonspor takımlarının 30.09.2019 sonu itibari ile kadrolarında bulunan futbolcuların mevkiilerine göre sınıflandırılmış ve tüm hesaplamalar bu oyuncular üzerinden yapılmıştır.

Tablo 1: 4 Büyüklerin Kadrolarında Yer Alan Futbolcuların Sayıları

\begin{tabular}{llllll}
\hline Takımlar & Kaleci & Defans & Orta Saha & Forvet & Toplam \\
\hline Beşiktaş & 3 & 8 & 10 & 4 & 25 \\
Fenerbahçe & 3 & 10 & 16 & 2 & 31 \\
Galatasaray & 3 & 10 & 14 & 2 & 29 \\
Trabzonspor & 3 & 8 & 11 & 4 & 26 \\
\hline
\end{tabular}

Tablo 1'i incelediğimizde kadrosunda en fazla oyuncu bulunduran takımın Fenerbahçe en az oyuncu bulunduran takımın ise Beşiktaş olduğunu görmekteyiz. Tüm takımların kaleci mevkiinde 3'er adet kaleci bulunurken, forvet mevkiinde Fenerbahçe ve Galatasaray takımlarında 2 Beşiktaş ve Trabzon takımlarında ise 4 adet kaleci bulunmaktadır. 
Tablo 2: 4 Büyük Takımın Futbolcularının Ortalama Transfermarkt Değerleri (Euro)

\begin{tabular}{lccccc}
\hline Takımlar & Kaleci & Defans & Orta Saha & Forvet & Ortalama \\
\hline Beşiktaş & 1.783 .333 & 3.662 .500 & 3.955 .000 & 2.512 .500 & 3.370 .000 \\
Fenerbahçe & 800.000 & 1.557 .500 & 3.882 .813 & 1.725 .000 & 2.695 .162 \\
Galatasaray & 1.783 .333 & 2.135 .000 & 6.685 .714 & 8.000 .000 & 4.700 .000 \\
Trabzonspor & 766.667 & 1.281 .250 & 2.645 .455 & 5.575 .000 & 2.459 .616 \\
\hline
\end{tabular}

Tablo 3: 4 Büyük Takımın Ortalama İnterpolasyon Değerleri (Euro)

\begin{tabular}{lccccc}
\hline Takımlar & \multicolumn{1}{l}{ Kaleci } & \multicolumn{1}{l}{ Defans } & Orta Saha & \multicolumn{1}{l}{ Forvet } & \multicolumn{1}{l}{ Toplam } \\
\hline Beşiktaş & 4.251 .901 & 5.455 .215 & 8.175 .002 & 7.051 .024 & 6.654 .062 \\
Fenerbahçe & 2.767 .313 & 3.555 .310 & 7.589 .958 & 14.042 .005 & 6.238 .012 \\
Galatasaray & 7.299 .018 & 7.994 .595 & 8.635 .640 & 33.388 .900 & 9.983 .440 \\
Trabzonspor & 2.544 .340 & 4.757 .149 & 9.209 .160 & 7.907 .518 & 6.870 .040 \\
\hline
\end{tabular}

Tablo 4: 4 Büyük Takımın Kadrolarında Yer Alan Futbolcuların Yaş Ortalamaları

\begin{tabular}{lrrrrr}
\hline Takımlar & \multicolumn{1}{l}{ Kaleci } & \multicolumn{1}{c}{ Defans } & Orta Saha & \multicolumn{1}{l}{ Forvet } & \multicolumn{1}{c}{ Ortalama } \\
\hline Beşiktaş & 2204 & 2907 & 2610 & 2705 & 2703 \\
Fenerbahçe & 2405 & 2512 & 2712 & 2812 & 2706 \\
Galatasaray & 2601 & 2806 & 2708 & 3001 & 2711 \\
Trabzonspor & 2208 & 2604 & 2504 & 2403 & 2502 \\
\hline
\end{tabular}

Tablo 5: 4 Büyük Takımın Futbolcularının İnterpolasyona Göre Yaş Ortalamaları

\begin{tabular}{lrrrrr}
\hline Takımlar & \multicolumn{1}{l}{ Kaleci } & \multicolumn{1}{c}{ Defans } & Orta Saha & \multicolumn{1}{l}{ Forvet } & \multicolumn{1}{c}{ Ortalama } \\
\hline Beşiktaş & 2502 & 2905 & 2605 & 2712 & 2703 \\
Fenerbahçe & 2708 & 2606 & 2709 & 2912 & 2711 \\
Galatasaray & 2803 & 2709 & 2706 & 2701 & 2707 \\
Trabzonspor & 2810 & 2802 & 2607 & 2503 & 2702 \\
\hline
\end{tabular}

Tablo 2'de transfermarkt sitesinin Beşiktaş, Fenerbahçe, Galatasaray ve Trabzonspor takımlarının 30.09.2019 tarihi itibari ile kadrolarında bulundurduğu futbolcuları için haziran ayı içerisinde yapmış olduğu değerlemelerinin ortalama tutarlarını göstermektedir. Tablo 3 'te ise bu değerler üzerinden kübik spline (şerit) interpolasyon fonksiyonu ile oluşturulan tutarlar yer 
almaktadır. Tablo 4'te futbolcular için değerlemenin yapıldığı tarihteki yaş ortalamaları yer alırken, Tablo 5'te 3. Tablodaki tutarların yaş-ay zamanındaki değerlerini göstermektedir.

Tabloları incelediğimizde Beşiktaş takımının kaleci mevkiinde oynayan futbolcularının yaş ortalaması 22 yaş 04 ay ortalaması ile 1.783.333 Euro değerindedir. Ancak Beşiktaş takımının kaleci mevkiinde yer alan 3 futbolcusunun (Loris Karius, Utku Yuvakuran ve Ersin Destanoğlu) fonksiyona göre hesaplanan en yüksek değerleri 12.464.126 Euro , 309.226 Euro ve 55.023 Euro olarak hesaplanmış bu değerlere ulaşacakları yaş-ay zamanları ise 25 yaş 02 ay, 19 yaş 11 ay 17 yaş 01 ay olarak ölçülmüştür. 3 kalecinin ortalama değerlerinin en yüksek değer olan 4.251.901 Euroya ulaştı̆̆1 zaman aralığı ise 25 yaş 02 ay olarak ölçülmüştür.

Tablo 6: Mevcut Değer İle Fonksiyon Değerleri Arasindaki Farklar (Euro)

\begin{tabular}{lcrrrr}
\hline Takımlar & \multicolumn{1}{l}{ Kaleci } & \multicolumn{1}{l}{ Defans } & \multicolumn{1}{l}{ Orta Saha } & \multicolumn{1}{l}{ Forvet } & \multicolumn{1}{l}{ Toplam } \\
\hline Beşiktaş & 2.468 .568 & 1.792 .715 & 4.220 .002 & 4.538 .524 & 13.019 .809 \\
Fenerbahçe & 1.967 .313 & 1.997 .810 & 3.707 .145 & 12.317 .005 & 19.989 .273 \\
Galatasaray & 5.515 .685 & 5.859 .595 & 1.949 .926 & 25.388 .900 & 38.714 .106 \\
Trabzonspor & 1.777 .673 & 3.475 .899 & 6.563 .705 & 2.332 .518 & 14.149 .795 \\
\hline
\end{tabular}

Tablo 7: Kadro Yaşı İle Fonksiyona Göre En Değerli Olacağı Yaş Farkları

\begin{tabular}{lccccc}
\hline Takımlar & \multicolumn{1}{l}{ Kaleci } & \multicolumn{1}{l}{ Defans } & Orta Saha & \multicolumn{1}{l}{ Forvet } & \multicolumn{1}{l}{ Ortalama } \\
\hline Beşiktaş & 0211 & 0003 & 0006 & 0008 & 0001 \\
Fenerbahçe & 0304 & 0006 & 0003 & 0100 & 0011 \\
Galatasaray & 0202 & 0009 & 0003 & 0212 & 0004 \\
Trabzonspor & 0603 & 0111 & 0103 & 0100 & 0201 \\
\hline
\end{tabular}

Tablo 6'yı incelediğimizde takımların kadrolarında yer alan futbolcuların ortalama değerleri ile fonksiyona göre hesaplanmış değerlerinin en yüksek olduğu zaman için tespit edilmiş değerler arasındaki farklar yer almaktadır. Buna göre Galatasaray takımının ortalama değeri 27 yaş 07 ay zamanında 9.983.440 Euro olması gerekirken, mevcut kadrosunun 27 yaş 11 ay zamanında ortalama değeri 4.700.000 Euro olduğu tespit edilmiş 4 mevkiinin ortalama farklarının toplamı 38.714.106 Euro olarak hesaplanmıştır. Bu farkın en büyük sebebi forvet mevkiinden kaynaklanmaktadır. Tablo 6'yı incelemeye devam ettiğimizde fonksiyona göre ölçülen değer ile mevcut kadro değeri arasında en az fark olan takım 13.019.809 Euro ile Beşiktaş'tır. Trabzonspor'un kadrosunun değeri ile fonksiyona göre ölçülen değer farkı 14.149.795 Euro olurken Fenerbahçe için 19.989.273 Euro olduğu gözlemlenmiştir. Fenerbahçe takımının da forvet mevkii kadrosunun ortalama değeri 28 yaş 12 ay ortalama ile 1.725.000 Euro olarak ölçülürken kübik spline interpolasyon fonksiyonuna göre 
29 yaş 12 ay zamanında 14.042.005 Euro değere ulaşması beklenmektedir. Tablo 7'de ise futbolcuların 30.09.2019 tarihi itibari ile yaş ortalamalanı ile en yüksek değere ulaşması beklenen yaş-ay zamanları arasındaki farkları göstermektedir.

Şekil 2: Radamel Falcao Garcia Zarate Transfermarkt ve İnterpolasyon Değeri Grafiği

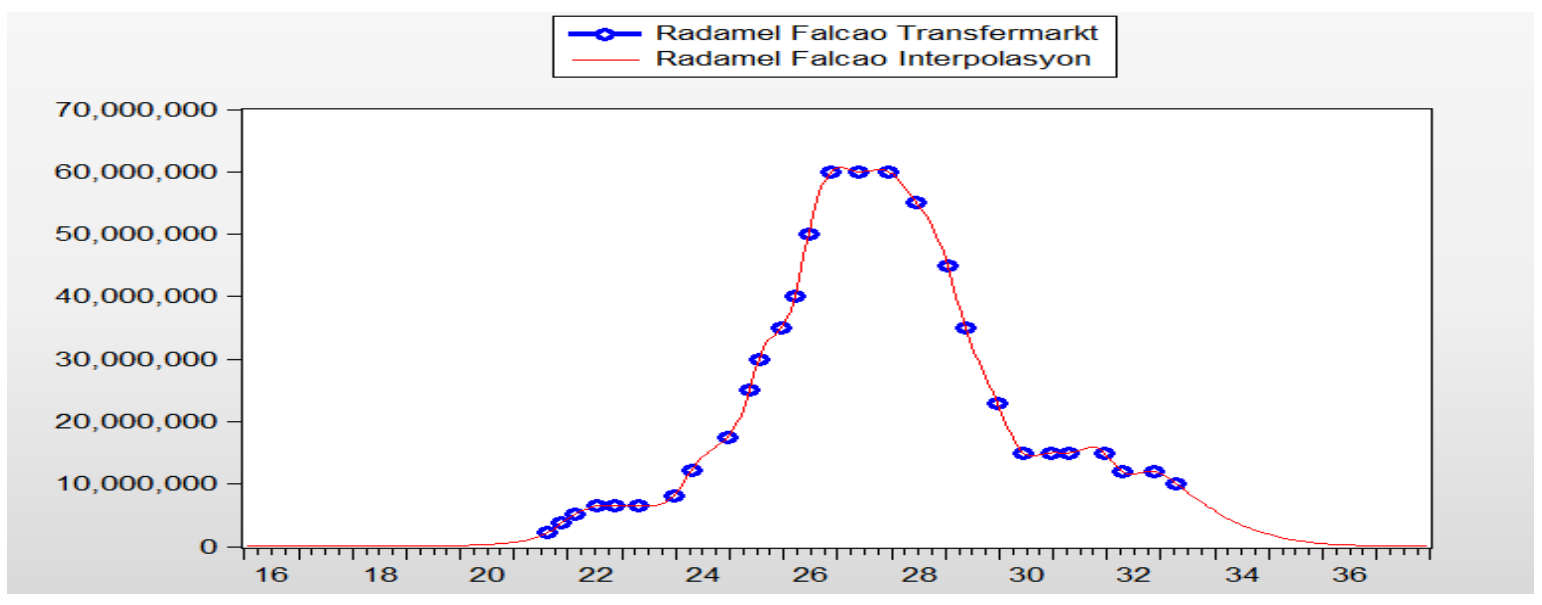

Şekil 2'de Galatasaray takımının kadrosunda bulunan Radamel Falcao Garcia Zarate isimli futbolcunun transfermarkt ve kübik spline interpolasyon fonksiyonuna göre oluşturulan grafiği yer almaktadır. Radamel Falcao'nun en yüksek piyasa değerine ulaştığı yaş zaman aralığı 27 yaş 12 ay ve 60.000.000 Euro olarak ölçülürken, Galatasaray takımına katıldıktan sonra 30.09.2019 tarihi itibari değeri 33 yaş 04 ay zamanında piyasa değerinin 10.000.000 Euro olduğu gözlemlenmiştir. Fonksiyona göre Falcao 27 yaş 10 ay zaman diliminde piyasa değerinin 60.362 .514 Euro olmas1 gerekiyordu.

\subsubsection{Menkul Kıymetleştirme}

Çalışmanın başında menkul kıymetleştirmenin tanımı yapılmıştı. Tanıma dikkat edildiğinde menkul kıymetlerin unsurları,

- Sahibine ortaklık veya alacaklılık hakkı sağlayan,

- Belirli bir tutarı temsil eden,

- Yatırım aracı olarak kullanılan,

- Dönemsel getiri sağlayan,

- Misli nitelikte olan ve seri halde çıkartılan,

- İbareleri aynı olan ve şartları SPK'da belirtilen kıymetli evraklardır.

$\mathrm{Bu}$ unsurlar göz önünde bulundurulduğunda futbol kulüpleri kadrolarında yer alan futbolcuların piyasa değerleri üzerinden menkul kıymetleştirme işlemi yapılabileceğini düşünmekteyiz. FIFA kuralları, futbolcunun sakatlık sebebi ile futbolu bırakması, başka bir takıma transfer olasıllğı sadece bir futbolcunun değeri üzerinden oluşturulacak menkul kıymetleştirme işlemini zorlaştırmaktadır. Bunun yerine mevkiilerine göre ayrılan futbolcular menkul kıymetleştirilecek dayanak varlık için aşağıda sayılan yöntem ile bulunabilir. 
$\checkmark \quad$ Menkul kıymetleştirme için futbol takımının kadrosunda bulunan tüm futbolcuları kaleci, defans, orta saha, forvet mevkiilerine göre sinıflandırılması.

Sınıflandırılması yapılan futbolcuların transfermarkt verilerine göre yaş-ay zamanına göre değerlerinin tespit edilmesi.

Her bir mevkiide oynayan futbolcunun futbola başlama ve futbolu bırakma yaş-ay zamanı belirlenir ve bu zamanlar için uygun bir değer tespit edilir.

$\checkmark \quad$ Her bir futbolcu için tüm yaş-ay zamanındaki değeri kübik spline (şerit) interpolasyon fonksiyonuna göre tespit edilir.

Tüm mevkiiler için tüm yaş-ay zamanındaki değerlerinin ortalaması alınarak, ortalama değerin en yüksek olduğu yaş-ay zamanı tespit edilir.

Şekil 3: Trabzonspor Takımı Kaleci Mevkii Değer Grafiği (Euro)

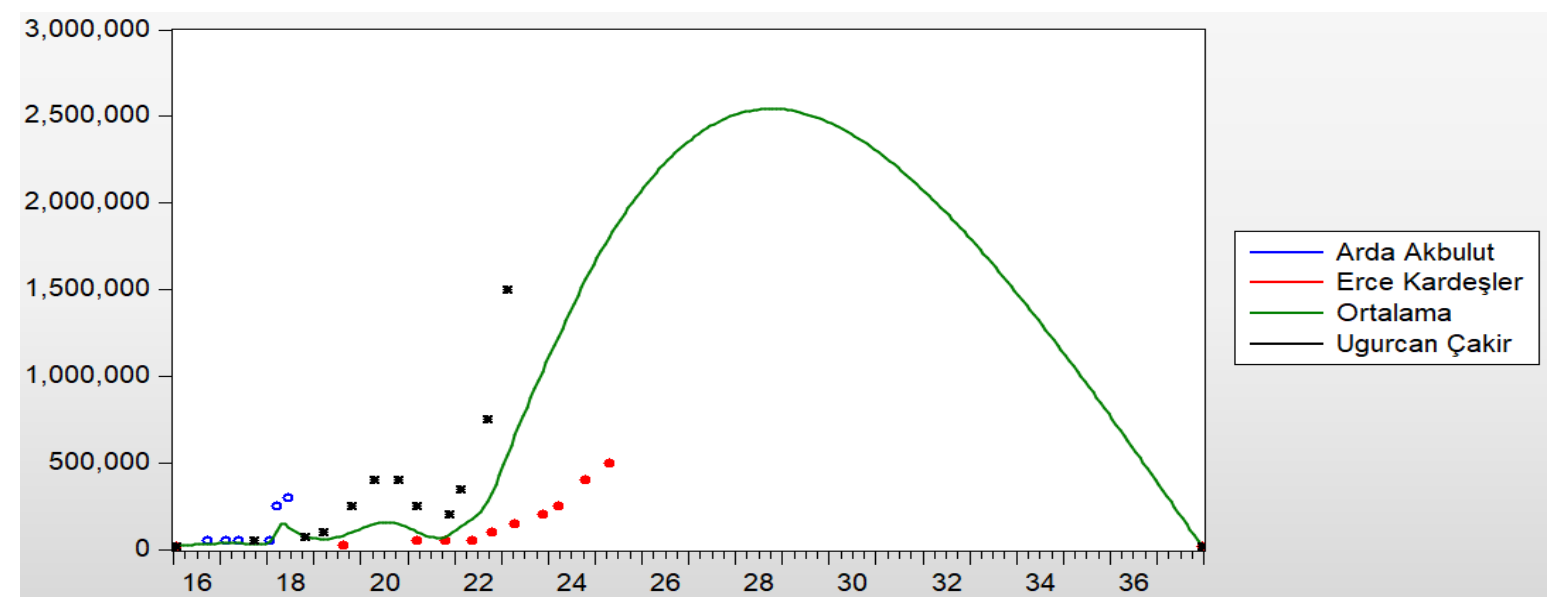

Şekil 3'ü incelediğimizde Trabzonspor takımının kaleci mevkiinde 3 tane futbolcu bulunduğunu görmekteyiz.. Transfermarkt değerlerine baktığımızda en yüksek tutarın 23 yaş 02 ay zamanında 1.500.000 Euro bedel ile Uğurcan Çakır’ da olduğu görülmektedir. Fonksiyon yardımı ile bu futbolcu grubunun ortalama değerlerinin en yüksek olduğu yaş-ay zaman diliminin 28 yaş 10 ay ve 2.544.340 Euro olacağı tespit edilmiştir. Trabzonspor takımının şu an için kadrosunda bulunan kalecilerinin ortalama değeri 766.667 Euro ortalama yaş-ay zamanı ise 22 yaş 04 ay olarak ölçülmüştür. Bu kaleci grubunun piyasa değeri 6 yıl 7 ay sonra ortalama olarak 1.777.673 Euro tutarında artış gösterebileceği tahmin edilmektedir. Dolayısı ile bu tutar kadar bir nakit akım oluşturulabilir ve kaleci mevkiinde oynayan oyuncu grubunun piyasa değerleri üzerinden menkul kıymetleştirilerek ihraç edilebilecektir. İhraç edilen menkul kıymet bir futbolcu olmadı̆̆ı için sakatlık, yaşlılık, başka bir takıma transfer olma gibi riskleri taşımayacaktır. 


\subsection{2 Örnek Çalışma}

Çalışmanın daha iyi anlaşılması için bir örnek ile açıklamak gerekirse, Trabzonspor takımının kaleci mevkiinde oynayan futbolcularının piyasa değerlerini dayanak varlık olacak şekilde bir menkul kıymet ihraç etmeye karar verdiğini düşünelim. Trabzonspor takımı kaleci mevkii için toplam 2.544.340 Euro değerinde 10.000 adet menkul kıymetleştirilmiş varlık ihraç ettiğini, menkul kıymetin vadesinin 5 yıl yıllık faiz oranının da Euro para birimi için yıllık \% 1,5 olduğunu varsayılırsa aşağıdaki tablodaki sonuçları elde ederiz.

Tablo 8: Trabzonspor Kaleci Mevkii Menkul Klymetleştirme Örneği

\begin{tabular}{|l|r|}
\hline Menkul Kıymet Adı & Trabzonspor Kaleci Mevkii \\
\hline Fonksiyona Göre Kaleci Mevkiinin En Yüksek Olduğu Tutar & $2.544 .340 €$ \\
\hline Fonksiyona Göre Kaleci Mevkiinin En Değerli Olduğu Yaş-Ay & 2810 \\
\hline İhraç Edilecek Menkul Kıymet Miktarı (Adet) & $254,43 €$ \\
\hline Birim Fiyat & $1,5 \%$ \\
\hline Yıllık Faiz Oranı & 5 Yıl \\
\hline Vade & $198.164 €$ \\
\hline Faiz Getirisi (Bileşik) & $2.346 .176 €$ \\
\hline 5 Yılın Sonundaki Net Değer & $766.667 €$ \\
\hline & 2204 \\
\hline Kaleci Mevkiinin Transfermarkt Verilerine Göre Net Değeri & $2.416 .874 €$ \\
\hline Kaleci Mevkiinin Yaş-Ay Zamanı & Yatırım Yapılabilir \\
\hline Fonksiyona Göre 5 Yıl Sonraki Değer (27 Yaş 04 Ay) & \\
\hline Yatırım Durumu &
\end{tabular}

Trabzonspor takımının 30.09.2019 sonu itibari ile kaleci mevkiinde oynayan 3 tane futbolcusu bulunduğunu söylemiştik. Bu futbolcuların transfermarkt piyasa değerleri ortalaması 766.667 Euro ve ortalama yaş-ay zamanı 22 yaş 04 aydır. Ancak Trabzonspor takımının bu mevkiide oynayan futbolcuları için en değerli olduğu zaman dilimi 28 yaş 10 ay ve ortalama 2.544.340 Euro olarak hesaplanmıştır. Bu mevkiide oynayan futbolcularının değeri fonksiyona göre önümüzdeki yıllar içerisinde artması beklendiğinden Trabzonspor takımı bugünden 2.544.340 Euro tutarında yıllık \% 1,5 oranında faiz veren bir menkul kıymet ihraç etmiştir. Kulüp 5 yıl sonunda yatırımcılarına 198.164 Euro faiz ödemesi yaptıktan sonra futbolcularının faiz ödemesi sonrasındaki ortalama net değerlerinin 2.416.874 Euro olması beklenmektedir. Dolayısı ile 5 yılın sonunda kulüp varlıklarını 30.09.2019 tarihine göre 1.650.207 Euro, faiz ödemesi çıkartıldıktan sonra net 1.452.043 Euro arttırması beklenmektedir. Yatırımcılar kaleci mevkiine yatırım yaparak faiz geliri kulüp de bu varlıklar üzerinden finans sağlamış olacaktır. 


\section{Bulgular}

Bu çalışma ile Türkiye'de bulunan 4 büyük kulüp olarak adlandırılan Beşiktaş, Fenerbahçe, Galatasaray ve Trabzonspor futbol kulüplerinin kadrolarında yer alan futbolcularının transfermarkt verileri üzerinden kübik spline interpolasyon fonksiyonu kullanılarak 16 yaş 01 ay ve 37 yaş 12 ay zaman aralığındaki tüm yaş-ay dönemi için değerleri tespit edilmiş, bu değerler dayanak varlık olarak kabul edilerek menkul kıymetleştirme işlemi yapılmıştır. 4 takımın kadrosunda yer alan futbolcuların 30.09.2019 tarihi itibari ile ortalama piyasa değerleri fonksiyon yardımı ile bulunan ortalama değerin altında kaldığı görülmüştür. Tutar olarak en büyük fark 38.714.106 Euro ile Galatasaray takımında olduğu tespit edilmiştir. $\mathrm{Bu}$ farkın da 25.388.900 Euro tutarındaki kısmı forvet mevkiinden kaynaklanmaktadır. Galatasaray takımının forvet mevkiinin mevcut yaş ortalaması 30 yaş 01 ay olduğu ancak fonksiyona göre en yüksek olması gereken yaş-ay zaman diliminin 27 yaş 01 ay olması gerektiği hesaplanmıştır. Forvet mevkiinin bugünkü yaş-ay zaman ve piyasa değeri fonksiyon değerinin üzerinde olduğu için gelecekte beklenen nakit akımlarının bugünkü piyasa değerinin altında kalmıştır. Bu sebep ile Galatasaray takımının forvet mevkii için ihraç edeceği bir menkul kıymete yatırım yapılması beklenmemektedir.

Çalışmada Galatasaray takımının mevcut kadrosunun 30.09.2019 tarihi itibari ile yaş ortalaması 29 yaş 11 ay olarak bulunurken fonksiyon yardımı ile bulunan ulaşması beklenen en yüksek yaş-ay zaman değerinin 27 yaş 07 ay olduğu tespit edilmiştir. Beşiktaş takımının her iki durumda yaş ortalamaları 27 yaş 03 ay olarak hesaplanmıştır. Fenerbahçe takımının mevcut kadrosunun yaş ortalaması 27 yaş 01 ay fonksiyon ortalaması ise 27 yaş 11 ay olduğu görülmüştür. Trabzonspor takımının kadrosunda yer alan futbolcuların yaş ortalaması 25 yaş 02 ay kübik spline interpolasyon yöntemi ile hesaplanan piyasa değerlerinin en yüksek olduğu yaş-ay zamanı 27 yaş 02 ay olarak hesap edilmiştir.

Trabzonspor takımının kaleci, defans ve orta saha mevkiilerinde yer alan futbolcularının 30.09.2019 tarihi itibari ile yaş-ay zaman değerleri fonksiyon yardımı ile bulunan yaş-ay zaman değerinin altında kalmışıtır. Forvet mevkiinde bulunan futbolcuların ortalama değerleri 5.575.000 Euro fonksiyona göre hesaplanan ortalama değerleri 2.332.518 Euro olduğu olarak tespit edilmiştir. Trabzonspor takımının kaleci, defans ve orta saha mevkiilerinin gelecekte beklenen nakit akımları değerleri 30.09.2019 tarihi itibari yaş-ay zaman değerinden yüksek olmasından dolayı menkul kıymetleştirme için en uygun varlıklar olduğu gözlemlenmiştir. 


\section{Sonuç}

$\mathrm{Bu}$ çalışma ile futbol kulüplerine yatırım yapmak isteyen yatırımcılara kulüplerin hisse senetlerinin dışında alternatif bir yatırım aracı sunulmuştur. Menkul kıymetleştirme işlemi mevkii üzerine yapılmaktadır. Çalışmada Trabzonspor takımının kaleci mevkiinin finansal değeri üzerine bir menkul kıymetleştirme işlemi yapılmıştır. Sadece bir futbolcunun finansal değeri üzerinden hesaplama yapılmamakta oynadığı mevkii üzerinden yapılmaktadır. Bu sebeple ihraç edilecek menkul kıymetin dayanak varlı̆ğ sabit bir yaşı olan, sakatlık ve transfer riski bulunmayan, haftalık performansına göre piyasa değeri değişim gösterecek olan oyuncu grubu olacaktır. $\mathrm{Bu}$ tarz durumlarda da kulüpler varlı̆ga dayalı menkul kıymet ihraç ederek kendilerine yeni bir finans oluşturması beklenmektedir.

Varlığa dayalı menkul kıymetler ikincil piyasalarda da işlem görmekte ve alım satıma konu olmaktadırlar. Kulüplerin haftalık performanslarına göre menkul kıymetlerin fiyatları değişebilir. Örnek vermek gerekirse Trabzonspor takımı gol yemediği bir maç sonunda kalecilerinin değerinin artması beklenir. Dolayısı ile kaleci mevkii menkul kıymetinin de değerinin artması beklenmektedir.

Türk takımlarının son yıllardaki transfer politikasından dolayı kadrolarında değeri düşmeye başlayan futbolcular yer almaktadır. Bu sebepten ötürü tüm takımlar için menkul kıymetleştirme işlemi yapılamamıştır. Bundan sonraki çalışmanın Almanya, Fransa, İngiltere, İspanya ve İtalya liglerinde mücadele eden takımlar üzerinden hesaplanması hedeflenmektedir. 


\section{Kaynakça}

Bernadette Minton, Tim Opler ve Sonya Stanton. (1997). "Asset Securitization Among Industrial Firms" Çalışma Kağıtları, Ohio State Universty, Colombus, ss:1-24

Burke Slyva ,Jennifer. (1999). "Bowie Bonds Sold For Far More Than A Song: The Securitization Of Intellectual Property As A Super-Charged Vehicle For High Technology Financing". Santa Clara High Technology Law Journal, Cilt:15, Sayı:1, ss:196-230.

Burns, Tom. (2007). "Structured Finance and Football Clubs: an Interim Assessment of the use of Securitisation". The Entertainment and Sports Law Journal, Cilt:4, Say1:3, ss:1-12. https://doi.org/10.16997/eslj.80.

Doğan, Sümeyye. (2013). "Advection Diffusion Denkleminin Genişletilmiş Kübik B-spline Sonlu Elemanlar Çözümleri", (Yüksek Lisans Tezi), Eskişehir Osmangazi Üniverstesi/Fen Bilimleri Enstitüsü,Eskiş̧ehir,http://openaccess.ogu.edu.tr:8080/xmlui/bitstream/handle/11684/806/10021511.pdf?sequ ence $=1$ \&isAllowed $=\mathrm{y}$.

FIFA. Regulations On The Status And Transfer Of Players (2015), https://resources.fifa.com/mm/document/affederation/administration/02/70/95/52/regulationsstatusandtransfe r_2015_e v051015_neutral.pdf, [Erişim Tarihi: 03.09.2019].

Li, Hongquan, Jin, Houzhong, ve Wang, Dan (2011). "Research on the Asset-Backed Securitization Financing of Large Stadium." International Business Research, Cilt:4, Sayl:2, ss:90-92. https://doi.org/10.5539/ibr.v4n2p90.

Maciel, Matteo ve Walton, Adam (2019). "Can player economic value rights be used as collateral?" International Sports Law Journal. Cilt:18, ss:185-209 https://doi.org/10.1007/s40318-018-0140-0.

Öcal, Nurcan (1994). "Türkiye'de Menkul Kıymetleştirme Uygulaması, Etkileri, Sorunlar ve Çözüm Önerileri" (Yüksek Lisans Tezi), Gazi Üniversitesi/Sosyal Bilimler Enstitüsü,Ankara, https://www.spk.gov.tr/Sayfa/Dosya/701, [Erişim Tarihi: 20.09.2019].

Sifma. (2019). US ABS Issuance and Outstanding. Retrieved from https://www.sifma.org/resources/research/us-abs-issuance-and-outstanding/, [Erişim Tarihi: 27.09.2019].

T.C Ticaret Bakanlığı (2019). Ekonomik Görünüm Mart 2019. Retrieved from https://ticaret.gov.tr/data/5b90d20a13b8760beca887fa/Ekonomik Gorunum_Mart.pdf, [Erişim Tarihi: 04.10.2019].

Transfermarkt (2019). Burak Yilmaz - Oyuncu profili 19/20 | Transfermarkt. Retrieved from https://www.transfermarkt.com.tr/burak-yilmaz/profil/spieler/34987, [Erişim Tarihi: 26.09.2019].

Tüysüz, Mustafa. (2011). Sermaye Piyasası Hukukunda Varlığa - İpoteğe Dayalı Menkul Kıymetleştirme. Ankara: Yetkin.

Weston, Rae. (2002). "Treading an Uneasy Path: The Securitisation of Gate Receipts". Proceedings of the Academy of Commercial Banking and Finance Cilt: 2 Sayı: 1 ss:49-52.

Yükselen, Adil. (2008). İstanbul Teknik Üniversitesi, HM504 Uygulamalı Sayısal Yöntemler Ders Notları, https://web.itu.edu.tr/yukselen/HM504/02-\%20E\%F0ri\%20uydurma\%20ve\%20interpolasyon.pdf, [Erişim Tarihi: 02.10.2019]. 